IP $\rightleftharpoons$ B

\title{
Viabilidade econômica da produção de Khaya ivorensis em pequena propriedade no Paraná
}

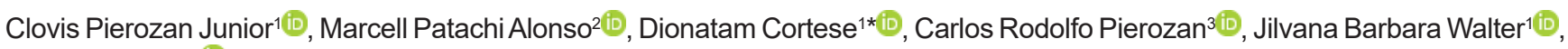 \\ Diaine Cortese ${ }^{1 \text { (iD }}$ \\ ${ }^{1}$ Instituto Federal do Paraná, Campus Palmas, Av. Bento Munhoz da Rocha Neto s/nº, PRT-280, Trevo da Codapar. CEP 85555-000, Palmas, PR, Brasil \\ ${ }^{2}$ Escola Superior de Agricultura "Luiz de Queiroz", Universidade de São Paulo, Av. Pádua Dias, CEP 13418-900, Piracicaba, SP, Brasil \\ 3Universidade Estadual de Londrina, Rod. Celso Garcia Cid, Pr 445 Km 380, CP. 10.011, CEP 86057-970, Londrina, PR, Brasil
}

"Autor correspondente:

dionatancortese@hotmail.com

Termos para indexação:

Fluxo de caixa

Índice de rentabilidade

Produção de madeira

Index terms:

Cash flow

Profitability index

Forestry production

Histórico do artigo

Received in 06/09/2017

Accepted in 18/07/2018

Published in 06/12/2018

doi: 10.4336/2018.pfb.38e201701495

\begin{abstract}
Resumo - O mogno africano (Khaya ivorensis) é uma espécie arbórea destinada à produção de madeira nobre. Apresenta elevado valor de mercado e boa adaptação edafoclimática à maior parte do território brasileiro. O objetivo do presente trabalho foi analisar a viabilidade econômica de plantio de mogno africano para produção de madeira nobre. Foi elaborado fluxo de caixa para um período de 20 anos. Os indicadores de viabilidade econômica calculados foram: valor presente líquido (VPL); taxa interna de retorno (TIR); payback; índice de rentabilidade e análise de sensibilidade, levando em consideração a variação de $60 \%$ para mais e para menos nos valores de investimento, receita e juros. O VPL calculado foi de R\$ 11.296,72; a TIR 16\%; o payback 19,92 anos; e o índice de rentabilidade foi de $\mathrm{R} \$ 2,82$ para cada $\mathrm{R} \$ 1,00$ investido. Na análise de sensibilidade, foi observado que apenas aumento acima de $15 \%$ nos juros, ou queda maior que $25 \%$ no valor da madeira tornaria o VPL negativo. Portanto, plantio de mogno africano é viável e apresenta baixa sensibilidade às variações do mercado.
\end{abstract}

\section{Economic viability of Khaya ivorensis production in small property in Paraná State, Brazil}

\begin{abstract}
The African mahogany (Khaya ivorensis) is a tree species, used to obtain high quality wood. It presents high market value and good adaptation to most soil and climatic conditions of Brazilian territory. The purpose of this study was to analyse the economic viability of African mahogany plantation to obtain wood of high quality. Cash flow has been drawn up for a period of 20 years. The economic viability indicators calculated were: net present value (NPV); Internal rate of return (IRR); payback; index of profitability and sensitivity analysis taking into account the variation of $60 \%$ for more and for less in investment values and interest revenue. The NPV was R $\$ 11,296.72$; the IRR 16\%; the payback 19.92 years and the profitability index was R $\$ 2.82$ for each $\mathrm{R} \$ 1.00$ invested. On sensitivity analysis, it was observed that only when increasing above $15 \%$ in interest, or fall greater than $25 \%$ in value of the the NPV would turn negative wood. Therefore, African mahogany plantationit, is feasible and presents low sensitivity changes in the market.
\end{abstract}

\section{Introdução}

O mogno africano (Khaya ivorensis) é uma das espécies preferidas para o reflorestamento em alguns Estados do Brasil, para a obtenção de madeira nobre (Teixeira, 2011). Essa espécie está sendo utilizada devido à facilidade em produzir mudas e, principalmente, pelo elevado valor econômico de sua madeira no mercado internacional (Falesi \& Baena, 1999).

No Oeste Africano, local de origem dessa espécie (Carvalho et al., 2010), há grande variação de condições de clima, relevo, ecológicas e edáficas (Danquah et 
al., 2011). É uma espécie que tolera grande variação climática, pelo elevado potencial adaptativo (Figueiredo et al., 2005). Por esse motivo, o mogno africano tem apresentado boa adaptação em grande parte do território brasileiro (Mathias, 2012), sendo a espécie madeireira exótica que apresenta melhor crescimento no Brasil (Teixeira, 2011). A capacidade adaptativa da espécie também é importante, como espécie alternativa para a diversificação das atividades desenvolvidas em uma propriedade rural e pelo potencial de agregação de valor. Esses pontos positivos do cultivo de mogno africano têm motivado a formação de novos plantios (Figueiredo et al., 2005).

Uma das características limitantes ao crescimento dessa espécie é a deficiência hídrica, em ambientes com baixa pluviosidade e/ou com distribuição irregular das chuvas ao longo do ano. Se não houver deficiência hídrica, mesmo que as temperaturas sejam mais baixas, como na região Sul do Brasil (Rosa, 2014), as árvores podem apresentar crescimento satisfatório. De acordo com o mapa de aptidão edafoclimática do mogno africano no Brasil, a região Central do Paraná é considerada apta ao cultivo, com restrições leves devido às temperaturas médias serem um pouco abaixo das ideais para a espécie. Ou seja, a espécie pode ser cultivada, mas seu crescimento será um pouco mais lento.

O interesse pelo cultivo de mogno africano em regiões mais frias do que as ideais para o desenvolvimento da cultura, como a região Central do Paraná, é justificado pela qualidade da madeira para uso em movelaria, faqueado, construção naval e em sofisticadas construções interiores (Ward et al., 2008; Ribeiro et al., 2017). Além disso, a madeira apresenta características tecnológicas atrativas, como facilidade no corte e grande potencial para exportação, pelo interesse do mercado europeu (Lamprecht, 1990).

Todas essas características positivas refletem no valor da madeira, que em 1999 rendeu em torno de US\$ 900,00 m-3 (Falesi \& Baena, 1999). Neste mesmo trabalho, os autores estimaram que quando as árvores plantadas em 1999 atingissem seu ponto de corte (em torno de 20 anos), o valor da madeira poderia alcançar US\$ 2.000,00 $\mathrm{m}^{-3}$ (valores em 1999). Esse é um valor considerado altamente atrativo, por não existir outro produto agrícola que o supere. A estimativa do valor em 20 anos superou o valor aplicado para essa espécie atualmente no mercado europeu, de $€ 675,00 \mathrm{~m}^{-3}$ (International Tropical Timber Organization, 2013), ainda sendo considerado muito competitivo e atrativo.
$\mathrm{O}$ rápido crescimento dessa espécie, em médio e longo prazos, proporciona elevado retorno financeiro (Gomes, 2010). Alguns estudos de viabilidade técnica e econômico-financeira sobre o cultivo de mogno africano no Brasil demonstram que a espécie poderá contribuir com a economia do país, pois haverá maior diversificação de atividades rurais, contribuindo para a geração de riquezas nacionais e internacionais.

Este trabalho tem como objetivo analisar a viabilidade econômica de uma floresta de mogno africano, para produção de madeira, na região central do estado do Paraná.

\section{Material e métodos}

Os dados utilizados foram provenientes de uma

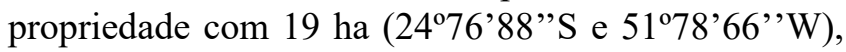
situada no município de Pitanga, região Central do estado do Paraná, a $952 \mathrm{~m}$ de altitude em relação ao nível do mar.

Segundo a classificação climática de Köppen, o município apresenta clima tipo $\mathrm{Cfb}$, caracterizado como clima temperado, com verão ameno, sem estação seca definida (Alvares et al., 2014). A precipitação média anual no município é de $2.000 \mathrm{~mm}$, sendo uniformemente distribuída durante o ano. $\mathrm{O}$ mês mais quente é fevereiro e apresenta temperatura média de $22^{\circ} \mathrm{C}$ (Sistema Meteorológico do Paraná, 2016). Durante o ano, há ocorrência de 10 a 25 geadas.

A área considerada para o cultivo foi de 1 ha, utilizada anteriormente como pastagem. O terreno apresenta baixa declividade e o solo foi classificado como Latossolo bruno distrófico (Sistema Brasileiro de Classificação de Solos, 1999). Foi realizada análise química do solo na camada $0,0-0,2 \mathrm{~m}$, apresentando os seguintes resultados: $\mathrm{pH}=5,1$; matéria orgânica do solo $=41,6 \mathrm{~g} \mathrm{dm}^{-3}$; teores de $\mathrm{P}($ Melich como extrator $)=$ $7,2 \mathrm{mg} \mathrm{dm}^{-3}$; K, Ca, Mg e CTC em pH 7,0 = 0,28; 2,9; 1,8 e $8,61 \mathrm{cmolc} \mathrm{dm}^{-3}$, respectivamente, com saturação de bases $=58 \%$.

Os custos e receitas estimados serviram para a elaboração do fluxo de caixa com horizonte de planejamento de 20 anos, desde a implantação da floresta até o único corte raso das árvores.

\section{Informações técnicas}

A finalidade da floresta de mogno africano é a produção de móveis e madeira sólida. O plantio das mudas foi realizado no mês de novembro de 2016, 
de maneira totalmente manual. O espaçamento utilizado para o plantio foi de 5,0 $\mathrm{m}$ x 5,0 m, conforme recomendado por Gomes (2010). Em alguns casos, recomendam-se espaçamentos menores (e.g., 2,5 m x 5,0 $\mathrm{m}$ ou $2,0 \mathrm{~m} \times 3,0 \mathrm{~m}$ ) para que seja realizado um desbaste quando a floresta estiver com 12 a 15 anos (Silva et al., 2016). Contudo, como a área é pequena, o pequeno volume de madeira gerado nesse desbaste poderia tornar o empreendimento economicamente inviável, por não ser garantido o interesse econômico para a compra de pequeno número de árvores finas, com menor valor de mercado.

Optou-se pela adoção de redução do investimento na implantação, utilizando menor quantidade de mudas e mão de obra, em plantio mais espaçado, visando apenas um corte. A população final projetada foi de 400 árvores $\mathrm{ha}^{-1}$. No levantamento dos custos, foram considerados os valores correspondentes de implantação (investimento) e manutenção (variável) das árvores.

A mão de obra utilizada nas operações foi contratada em regime de diária, com valores estabelecidos pela média praticada na região.

A adubação foi realizada manualmente nas covas, no momento da implantação da cultura (adubação de base) e posteriormente em cobertura durante o desenvolvimento da floresta. Foram planejadas cinco aplicações de fertilizante, uma no momento da implantação da cultura e as outras quatro em cobertura, a cada 4 anos, quando as árvores atingissem 4, 8, 12 e 16 anos.

\section{Custos de implantação e de manutenção}

Os custos de implantação, realizada em 2016, foram compostos por mão-de-obra, análise de solo, correção de solo, controle de formigas, controle de plantas invasoras, adubo, plantio e replantio.

O valor pago por diária para a mão de obra foi de $\mathrm{R} \$$ 60,00 , que era o preço normalmente praticado na região. Sua necessidade em dias foi estabelecida conforme os procedimentos realizados e o rendimento médio por homem. Foi realizada uma análise de solo, no valor de $\mathrm{R} \$ 45,00$. A calagem foi realizada dois meses antes do plantio, com aplicação de $2000 \mathrm{~kg} \mathrm{ha}^{-1}$ de calcário. A adubação na implantação da cultura foi feita no momento da abertura das covas, utilizando $250 \mathrm{~kg} \mathrm{ha}^{-1}$ da formulação 04-30-10 + micro, definida com base na análise de solo.

$\mathrm{Na}$ implantação, foi realizado o combate inicial às formigas (Atta e Acromyrmex) e o controle de plantas daninhas. O replante foi realizado, de forma manual, estimando-se uma perda média de $20 \%$ do total de mudas plantadas.

Os custos projetados com a manutenção foram compostos por gastos com mão de obra, adubações de cobertura, controle de formigas, controle químico de plantas invasoras, impostos e custo de oportunidade da terra.

A adubação de cobertura foi realizada aos 12,24 , 48 e 60 meses após o plantio, utilizando $300 \mathrm{~kg} \mathrm{ha}^{-1}$ da formulação de NPK (20-05-20), em cada adubação.

$\mathrm{O}$ controle de formigas foi realizado durante cinco anos, com dois controles por ano. As plantas daninhas foram controladas quimicamente aos $6,12,18,24,36$, 48 e 60 meses, até as árvores fecharem o dossel.

O custo de oportunidade da terra foi estimado conforme o valor médio de rentabilidade obtida em uma área produtora de soja da região. Portanto, considerou-se que o produtor poderia destinar a área para a implantação da floresta ou para plantio de soja, estimando-se a rentabilidade média em soja em R \$ 3.500,00 ano ${ }^{-1}$ ha $^{-1}$.

\section{Receitas}

As receitas estimadas foram provenientes do corte final com vinte anos, período médio em que as árvores atingem seu ponto de corte, com a venda da madeira em pé. O valor médio obtido da venda das árvores foi estimado dentro dos valores atuais que são pagos no mercado brasileiro, que por sua vez é baseado nos valores praticados no mercado europeu, ficando em $€$ $675,00 \mathrm{~m}^{-3}$ (International Tropical Timber Organization, 2013), equivalente a $\mathrm{R} \$ 1.988,92 \mathrm{~m}^{-3}$, considerando o valor médio histórico dos últimos 10 anos do câmbio de $\mathrm{R} \$ 2,9466$ por $€ 1,00$ (Uol Economia, 2017).

\section{Fluxo de caixa}

As saídas do fluxo de caixa foram representadas pelos custos de implantação e manutenção da floresta e as entradas foram provenientes da venda em pé da produção de mogno africano.

$\mathrm{Na}$ avaliação financeira do projeto, foi considerada a taxa do Sistema Especial de Liquidação e Custódia (taxa Selic acumulada) de outubro de 2015 a outubro de 2016 (12 meses), período de realização do trabalho. Utilizouse como parâmetro a taxa mínima de atratividade (TMA) de 4,4\% ao ano. A taxa corresponde ao juro real foi calculada pela taxa de juros nominal do Selic em 14,25\%, descontando-se a inflação no ano de 2015, 
que foi de foi de 9,85\%, segundo o Índice Nacional de Preços ao Consumidor Amplo (IPCA) (Banco Central do Brasil, 2016a).

Com o fluxo de caixa estabelecido, foi possível a análise da viabilidade econômica da implantação da floresta de mogno africano, visando à produção de madeira para a fabricação de móveis.

\section{Indicadores econômicos}

Antes da implantação de qualquer projeto deve ser realizado testes de viabilidade econômica, a fim de observar se as receitas irão superar os custos (Rezende \& Oliveira, 2001).

A análise de viabilidade econômica foi realizada a partir do cálculo de: valor presente líquido (VPL), taxa interna de retorno (TIR), payback, análise de sensibilidade e índice de lucratividade.

\section{Valor presente líquido}

Esse indicador econômico de viabilidade de um projeto representa o cálculo do valor presente de um fluxo de caixa projetado de um investimento, em que são consideradas todas as entradas e saídas de caixa, levando-se em consideração a taxa de juros (Dal Zot, 2006). A taxa de juros utilizada foi de $14,25 \%$, balizada pela taxa Selic 2016 (Banco Central do Brasil, 2016b), sendo o VPL calculado pela equação 1).

$$
\mathrm{VPL}=\frac{\mathrm{FC} 1}{1+\mathrm{i}}+\frac{\mathrm{FC} 2}{1+\mathrm{i}}+\frac{\mathrm{FCn}}{(1+\mathrm{i})^{\mathrm{n}}}-\mathrm{FC} 0
$$

Onde: $\mathrm{VPL}=$ valor presente líquido, $\mathrm{FCn}=$ retorno, na data $t$, do fluxo de caixa, considerando $t$ em anos, variando de 1 até $\mathrm{n} ; \mathrm{FC} 0=$ investimento inicial; $\mathrm{i}=$ custo do capital.

Quando se aplica o VPL para a tomada de decisão, entende-se que se o valor for positivo o projeto é viável economicamente e deve ser aceito. Se o VPL $=0$, o projeto não terá valor para acrescentar à empresa, mas retorna a expectativa de ganho do investidor, sendo considerado aceito, mas se o VPL for negativo, não deve ser aceito.

\section{Taxa interna de retorno}

Essa análise indica qual taxa de juros anula o VPL (Lapponi, 1996). O valor obtido com o cálculo da TIR caracteriza a taxa de remuneração do capital investido (Afonso Júnior et al., 2006). A TIR é obtida através do fluxo de caixa projetado, não tendo necessidade de arbitrar um valor para a taxa de desconto (juros), sendo calculada utilizando a equação 2 .

$$
\mathrm{TIR}=\sum_{\mathrm{t}=1}^{\mathrm{n}} \frac{\mathrm{FCt}}{(1+\mathrm{i})^{\mathrm{t}}}=0
$$

Onde: $\mathrm{TIR}=$ taxa interna de retorno $; \mathrm{i}=$ taxa de retorno $; \mathrm{FCt}$ $=$ fluxo de caixa no período de tempo; $\mathrm{t}=$ tempo de desconto de cada entrada de caixa.

Em uma decisão de investimento, considera-se que se o valor da TIR for superior ao valor do custo de capital o projeto é economicamente viável. Se for inferior, rejeitase o projeto, pois não criará valor.

\section{Payback descontado}

Esse indicador define o período de tempo necessário para que os lucros de um investimento recuperem o capital que foi investido (Gitman, 2002). O payback descontado, analisado nesse trabalho (equação 3), levou em consideração o custo do dinheiro no tempo.

$$
\mathrm{I}=\sum_{\mathrm{t}=1}^{\mathrm{t}} \frac{\mathrm{FCt}}{(1+\mathrm{K})^{1}} \sum_{\mathrm{t}=1}^{\mathrm{t}} \frac{\mathrm{FCt}}{(1+\mathrm{K})^{1}}
$$

Onde: $\mathrm{I}=$ capital inicial investido $; \mathrm{FCt}=$ fluxo de caixa no período de tempo $\mathrm{t} ; \mathrm{K}=$ custo de capital; $\mathrm{t}=$ tempo para recuperação do capital aplicado.

\section{Análise de sensibilidade}

Esse tipo de estudo permite que se verifique o quanto a rentabilidade do projeto é afetada pela variação da taxa de juros, receitas e despesas. Foram estabelecidos os limites superior e inferior e a partir daí variaram-se os parâmetros. Foi calculado, para cada valor, uma VPL, sendo obtido um referencial da sensibilidade de cada variável. O resultado permite descobrir quais são os parâmetros mais sensíveis que podem inviabilizar o projeto e, a partir de então, dar atenção especial a eles, como por exemplo a variação dos juros conforme o cenário macroeconômico; possibilidade do aumento no preço de mudas, entre outros (Samanez, 2009).

Para a análise de sensibilidade, foram trabalhadas variações na receita, nos custos e na taxa de juros. Foram analisados valores na faixa de $\pm 60 \%$, escalonados de 5 em 5\%. Essa grande amplitude foi estipulada levandose em consideração as flutuações que podem ocorrer na economia (e.g., juros). Sabe-se que no período de $17 / 01 / 2013$ a $06 / 03 / 2013$ a taxa Selic foi de $7,12 \%$, ou seja, $50 \%$ do valor atual, e de 24/04/2003 a 21/05/2003, a mesma taxa foi de 26,32 , ou seja, $85 \%$ maior do que a atual. Além disso, o valor da madeira pode variar, sendo esperado que o valor aumente devido à maior demanda e menor oferta (Banco Central do Brasil, 2016a). 


\section{Índice de rentabilidade relativo e percentual}

Esse índice é medido pela relação entre o valor atualizado dos fluxos operacionais líquidos de entrada e de saída de caixa. Na prática, indica o retorno obtido pela empresa para cada $R \$ 1,00$ investido. Todos os resultados são expressos em valores atualizados pela taxa mínima de atratividade. $\mathrm{O}$ índice de rentabilidade relativo foi calculado utilizando-se a equação 4 . O índice de rentabilidade percentual difere do relativo apenas por demonstrar os retornos em porcentagem (Lapponi, 1996).

$$
\mathrm{IL}=\frac{\sum_{\mathrm{j}=1}^{\mathrm{n}} \frac{\mathrm{FCj}}{(1+\mathrm{i})^{\mathrm{j}}} \sum_{\mathrm{j}=1}^{\mathrm{n}} \frac{\mathrm{FCj}}{(1+\mathrm{i})^{\mathrm{j}}}}{\operatorname{abs}\left(\mathrm{FC}_{0}\right) \text { abs }\left(\mathrm{FC}_{0}\right)}
$$

Onde: $\mathrm{IL}=$ índice de lucratividade ou rentabilidade; $\mathrm{FCj}$ $=$ fluxo de caixa no período $\mathrm{j} ; \mathrm{i}=$ taxa de juros; $\mathrm{j}=$ período de tempo analisado; $\mathrm{n}=$ número de períodos; $\mathrm{FC} 0=$ fluxo de caixa do ano 0 .

\section{Resultados}

$\mathrm{Na}$ implantação da floresta, foram investidos em um hectare R\$ 6.222,50 (Tabela 1). Desse total, a maior despesa foi representada pelas mudas que custaram $\mathrm{R} \$$ $3.360,00$, que corresponde a $54 \%$ do total investido nessa etapa. Os demais itens, que correspondem ao maior percentual gasto, foram (em ordem decrescente): mão de obra para abertura de covas e adubação de plantio (26\%), fertilizante $(8,4 \%)$, e calcário $(4,8 \%)$. Esses itens somados correspondem a $93,2 \%$ dos custos de implantação.

Estima-se que o total gasto com os custos variáveis de manutenção totalizaram, em 20 anos de projeto, R\$ 74.560,80 (Tabela 2), equivalendo, em média, a $\mathrm{R} \$ 3.728,04 \mathrm{ha}^{-1} \mathrm{ano}^{-1}$. O custo de oportunidade da terra foi estimado em $\mathrm{R} \$ 70.000,00$ neste período, correspondendo a $93,9 \%$ do total. O próximo item mais alto em custo foi adubação de cobertura, que representou apenas $3,5 \%$ do total gasto.

A única fonte de receitas do projeto foi o corte raso de 400 árvores ha ${ }^{-1}$ após 20 anos de desenvolvimento da floresta. A produção de cada árvore foi estimada em cerca de $0,75 \mathrm{~m}^{3}$ de madeira.
Tabela 1. Custos de implantação por hectare de mogno africano em Pitanga, PR.

Table 1. Implantation costs per hectare of African mahogany in Pitanga, PR.

\begin{tabular}{|c|c|c|c|c|}
\hline Operações & Unidade & $\begin{array}{c}\text { Custo por } \\
\text { unidade } \\
\text { (R\$) }\end{array}$ & Quantidade & $\begin{array}{l}\text { Total } \\
\text { (R\$) }\end{array}$ \\
\hline \multicolumn{5}{|c|}{ Preparo de solo e plantio } \\
\hline $\begin{array}{c}\text { Mão de obra } \\
\text { para abertura } \\
\text { de covas }+ \\
\text { adubação e } \\
\text { plantio }\end{array}$ & d homem ${ }^{-1}$ & 60,00 & 27 & $1.620,00$ \\
\hline Análise de solo & Amostra & 45,00 & 1 & 45,00 \\
\hline \multicolumn{5}{|c|}{ Correção do solo } \\
\hline $\begin{array}{c}\text { Calcário }+ \\
\text { Frete }\end{array}$ & $\mathrm{kg}$ & 0,15 & 2.000 & 300,00 \\
\hline \multicolumn{5}{|c|}{ Controle de formigas } \\
\hline Mão de obra & d homem ${ }^{-1}$ & 60,00 & 1 & 60,00 \\
\hline Formicida & $\mathrm{kg}$ & 15,00 & 4 & 60,00 \\
\hline \multicolumn{5}{|c|}{ Controle de plantas daninhas } \\
\hline Mão de obra & d homem ${ }^{-1}$ & 60,00 & 1 & 60,00 \\
\hline Herbicida & $\mathrm{L}$ & 14,50 & 5 & 72,50 \\
\hline \multicolumn{5}{|c|}{ Fertilizante } \\
\hline $\begin{array}{l}\text { 04-30-10+ } \\
\text { micro }\end{array}$ & $\mathrm{kg}$ & 2,10 & 250 & 525,00 \\
\hline Replantio & d homem ${ }^{-1}$ & 60,00 & 2 & 120,00 \\
\hline Mudas & Un. & 7,00 & 480 & $3.360,00$ \\
\hline Total & & & & $6.222,50$ \\
\hline
\end{tabular}

Dessa forma, considerando-se o preço médio de $€$ $675,00 \mathrm{~m}^{-3}$ (International Tropical Timber Organization, 2013), e o valor histórico do câmbio $\mathrm{R} \$ 2,9466$ por $€$ 1,00 , considerou-se o valor de venda de $\mathrm{R} \$ 1.988,92 \mathrm{~m}^{-3}$ de mogno africano, resultando em uma receita ao final dos 20 anos de $\mathrm{R} \$ 596.676,00$ ha $^{-1}$.

$\mathrm{O}$ valor presente líquido (VPL) observado foi de R $\$$ $11.296,72$ e a taxa interna de retorno (TIR) $16 \%$, valor $363 \%$ superior à taxa mínima de atratividade (TMA) esperada, que foi $4,4 \%$ após desconto da inflação. Se também fossem descontados os $9,85 \%$ da inflação, de $16 \%$ calculado para a TIR, o TIR seria $6,15 \%$, e este representaria um retorno $39 \%$ maior do que a TMA. Os índices de rentabilidade indicaram que, para cada $\mathrm{R} \$$ 1,00 investido, o retorno foi de $\mathrm{R} \$ 2,82$, equivalente a $1,82 \%$ (Tabela 3 ). Os altos valores de VPL, TIR maior do 
que TMA e os elevados índices de rentabilidade indicam que o projeto é viável. Entretanto, como as receitas só serão obtidas através de um corte raso, após 20 anos, o Payback descontado é longo (19,92 anos).

Tabela 2. Custos de manutenção por hectare da cultura do mogno africano em Pitanga, PR.

Table 2. Maintenance costs per hectare of African mahogany in Pitanga, PR.

\begin{tabular}{|c|c|c|c|c|}
\hline Operações & Unidade & $\begin{array}{c}\text { Custo } \\
\text { unidade (R\$) } \\
\end{array}$ & Quantidade & Total (R\$) \\
\hline \multicolumn{5}{|c|}{ Adubação de cobertura } \\
\hline Mão de obra & d homem ${ }^{-1}$ & 60,00 & 4 & 240,00 \\
\hline $20-05-20$ & $\mathrm{~kg}$ & 2,05 & 1.200 & $2.460,00$ \\
\hline \multicolumn{5}{|c|}{ Controle de formigas } \\
\hline Mão de obra & $\mathrm{d}_{\text {homem }}{ }^{-1}$ & 60,00 & 10 & 600,00 \\
\hline Formicida & $\mathrm{kg}$ & 15,20 & 10 & 152,00 \\
\hline \multicolumn{5}{|c|}{ Controle de daninhas } \\
\hline Mao de obra & $\mathrm{d}$ homem $^{-1}$ & 60,00 & 7 & 420,00 \\
\hline Herbicida & $\mathrm{L}$ & 16,40 & 6 & 688,80 \\
\hline $\begin{array}{l}\text { Custo de } \\
\text { oportunidade } \\
\text { da terra }\end{array}$ & $\mathrm{R} \$ \mathrm{ha}^{-1} \mathrm{ano}^{-1}$ & $3.500,00$ & 20 & $70.000,00$ \\
\hline
\end{tabular}

Tabela 3. Indicadores econômicos valor presente líquido (VPL), taxa interna de retorno (TIR), payback descontado, (VPL) sem descontar o investimento, índice de rentabilidade relativo e percentual do cultivo de mogno africano.

Table 3. Economic indicators net present value (VPL), internal rate of return (TIR), discounted payback, (VPL) without discounting the investment, relative profitability index and percentage of the African mahogany crop.

\begin{tabular}{lc}
\hline \multicolumn{1}{c}{ Indicadores } & Valores \\
\hline (VPL) & $\mathrm{R} \$ 11.296,72$ \\
(TIR) & $16 \%$ \\
Payback descontado & 19,92 anos \\
(VPL) sem descontar o investimento & $\mathrm{R} \$ 17.519,22$ \\
Índice de rentabilidade relativo & $\mathrm{R} \$ 2,82$ \\
Índice de rentabilidade percentual & $181,54 \%$ \\
\hline
\end{tabular}

\section{Análise de sensibilidade}

Como se pode observar na Figura 1, o projeto é bastante robusto, pois em poucas simulações o VPL apresentou valores negativos. Observa-se que o VPL suporta um aumento de 30\% no investimento, sendo que acima deste o VPL torna-se negativo. Entretanto, se houverem reduções nas despesas em $60 \%$, o VPL poderia chegar a $\mathrm{R} \$ 29.451,16$ (Tabela 4). Observa-se que, caso haja decréscimo no preço da madeira da ordem de $30 \%$, o VPL torna-se negativo ( $\mathrm{R} \$-1.169,52$ ), e pode chegar a R\$ - $13.635,76$, no caso de queda de $60 \%$ no preço da madeira.

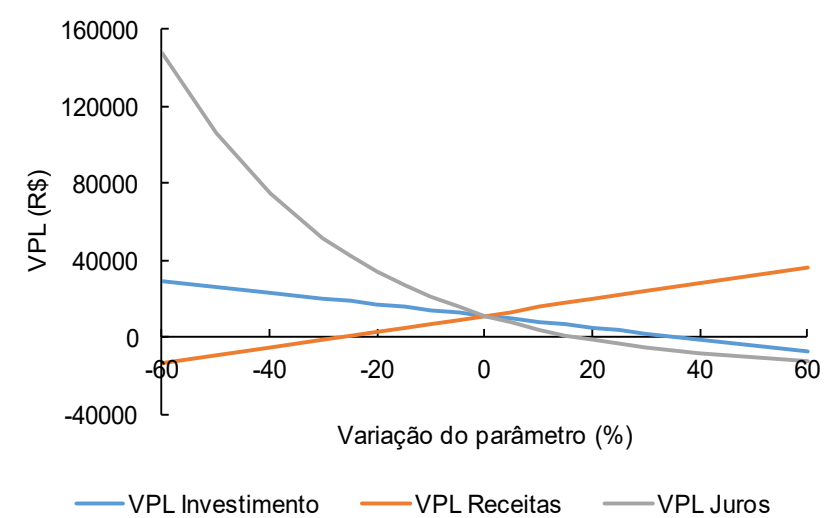

Figura 1. Flutuação do valor presente líquido (VPL) em função da variação em $60 \%$ para mais ou para menos do investimento, receita e taxa de juros.

Figure 1. Fluctuation of the net present value (VPL) as a function of the $60 \%$ variation for more or less of the investment, revenue and interest rate. 
Tabela 4. Flutuação do valor presente líquido (VPL) em relação à variação do investimento, receita e taxa de juros.

Table 4. Net present value fluctuation (VLP) in relation to variation of investment, revenue and interest rates.

\begin{tabular}{|c|c|c|c|c|c|c|}
\hline $\begin{array}{l}\text { Variação do } \\
\text { Parâmetro }\end{array}$ & $\begin{array}{c}\text { Investimento } \\
\text { (R\$) }\end{array}$ & Receitas (R\$) & $\begin{array}{c}\text { Juros } \\
(\%)\end{array}$ & $\begin{array}{c}\text { VPL } \\
\text { investimento } \\
(\mathrm{R} \$)\end{array}$ & $\begin{array}{c}\text { VPL receita } \\
\text { (R\$) }\end{array}$ & $\begin{array}{c}\text { VPL juros } \\
\text { (R\$) }\end{array}$ \\
\hline-60 & $-32.313,32$ & $238.670,27$ & 5,70 & $29.451,16$ & $-13.635,7$ & $147.987,1$ \\
\hline-50 & $-40.391,65$ & $298.337,84$ & 7,13 & $26.425,42$ & $-9.480,35$ & $106.171,5$ \\
\hline-40 & $-48.469,98$ & $358.005,41$ & 8,55 & $23.399,68$ & $-5.324,93$ & $74.957,86$ \\
\hline-30 & $-56.548,31$ & $417.672,97$ & 9,98 & $20.373,94$ & $-1.169,52$ & $51.622,18$ \\
\hline-25 & $-60.587,48$ & $447.506,76$ & 10,69 & $18.861,07$ & 908,19 & $42.259,33$ \\
\hline-20 & $-64.626,64$ & $477.340,54$ & 11,40 & $17.348,20$ & $2.985,89$ & $34.158,24$ \\
\hline-15 & $-68.665,81$ & $507.174,32$ & 12,11 & $15.835,33$ & $5.063,60$ & $27.148,43$ \\
\hline-10 & $-72.704,97$ & $537.008,11$ & 12,83 & $14.322,46$ & $7.141,31$ & $21.083,06$ \\
\hline-5 & $-76.744,14$ & $566.841,89$ & 13,54 & $12.809,59$ & $9.219,01$ & $15.835,56$ \\
\hline 0 & $-80.783,30$ & $596.675,68$ & 14,25 & $11.296,72$ & $11.296,72$ & $11.296,72$ \\
\hline 5 & $-84.822,47$ & $626.509,46$ & 14,96 & $9.783,85$ & $13.374,42$ & $7.372,26$ \\
\hline 10 & $-88.861,63$ & $656.343,24$ & 15,68 & $8.270,98$ & $15.452,13$ & $3.980,73$ \\
\hline 15 & $-92.900,80$ & $686.177,03$ & 16,39 & $6.758,11$ & $17.529,84$ & $1.051,68$ \\
\hline 20 & $-96.939,96$ & $716.010,81$ & 17,10 & $5.245,24$ & $19.607,54$ & $-1.475,85$ \\
\hline 25 & $-100.979,13$ & $745.844,59$ & 17,81 & $3.732,37$ & $21.685,25$ & $-3.654,63$ \\
\hline 30 & $-105.018,29$ & $775.678,38$ & 18,53 & $2.219,50$ & $23.762,96$ & $-5.530,41$ \\
\hline 40 & $-113.096,62$ & $835.345,95$ & 19,95 & $-806,25$ & $27.918,37$ & $-8.526,32$ \\
\hline 50 & $-121.174,95$ & $895.013,51$ & 21,38 & $-3.831,99$ & $32.073,78$ & $-10.722,0$ \\
\hline 60 & $-129.253,28$ & $954.681,08$ & 22,80 & $-6.857,73$ & $36.229,19$ & $-12.312,5$ \\
\hline Amplitude & $-96.939,96$ & $716.010,81$ & 17,10 & $36.308,89$ & $49.864,95$ & $160.299,6$ \\
\hline
\end{tabular}

\section{Discussão}

A projeção da produção obtida foi menor do que os resultados obtidos por Gomes (2010) e Parque Florestal (2016), em floresta estabelecida em ambiente com temperatura mais elevada. Acredita-se que devido ao rigoroso inverno que ocorre na região deste trabalho, o crescimento das árvores possa ser mais lento.

O plantio de mogno africano se mostrou mais sensível às variações na redução da receita do que às variações no aumento dos custos (Tabela 4). De acordo com Tsukamoto Filho et al. (2003), isso ocorre quando o preço da madeira apresenta valor muito alto no mercado.

Apesar de haver flutuações nos preços pagos por madeira, uma queda da ordem de $50 \%$ é pouco provável, uma vez que o corte de madeira ilegal vem sendo combatido, diminuindo a quantidade do produto no mercado, o que por sua vez causa aumento nos preços dos produtos legais à venda. Entretanto, se houver mudança nos hábitos e preferências do consumidor, ou se a quantidade de madeira legal produzida aumentar demasiadamente, os valores unitários podem sofrer queda. Outro ponto a se considerar sobre o valor presente líquido (VPL) das receitas é a perda na produtividade. Caso haja ataque de pragas, doenças, competição com plantas daninhas ou incêndios que façam com que a produção reduza em $50 \%$, o projeto tornar-se-á inviável.

$\mathrm{Na}$ análise de sensibilidade, o fator que mais influenciou o VPL foi o aumento da taxa de juros. Um aumento de $20 \%$ na taxa Selic fará com que a taxa passe de 14,25 para $17,1 \%$, o que tornaria o VPL negativo. Portanto, o aumento da inflação, que é um dos fatores mais eminentes que pode fazer com que a taxa cresça, pode tornar o projeto inviável. Mesmo assim, considerando os últimos 17 anos (1999-2016), observa-se que a inflação média, segundo o IPCA, ficou em 6,87\% ao ano (Banco Central do Brasil, 2016c), menor do que o índice de 2015 (9,85\%) considerado 
nesse trabalho. Dentre os dados da série histórica desde 1999, somente em 2002, ano em que apresentou índice de $12,53 \%$, a inflação foi maior do que o índice de 2015 (Uol Economia, 2017).

Comparando-se os resultados da análise econômica do presente estudo com outros sistemas florestais, observamos que o cultivo de mogno africano, nas condições estudadas, é uma atividade bastante lucrativa. Em estudo com um sistema de produção agro-silvopastoril com eucalipto no cerrado o VPL foi de US\$ 79,74 , e foi considerada uma opção economicamente viável se pelo menos $5 \%$ da madeira fosse destinada para serraria, sendo o restante destinado para energia ou para outra finalidade com valor igual ou mais alto no mercado. Nesse sistema, o aumento de mais de 5,38\%, simultaneamente, em todos os custos de produção também levaria à inviabilidade econômica do projeto (Oliveira et al., 2000), enquanto que no presente estudo o aumento das receitas em $25 \%$ ainda não resultaria em uma VPL negativa.

Em cultivo do eucalipto, no estado de São Paulo, Janoselli et al. (2016) observaram VPL negativo em $\mathrm{R} \$ 40.808,70$ e a TIR $=3,41 \%$, portanto inviável, não apresentando rentabilidade para o investidor. Valores mais baixos de VPL foram obtidos por Vitale \& Miranda (2010) no estado do Paraná para plantios de eucalipto e pinus. Esses autores observaram VPL de R \$ 38.074,71 ha $^{-1}$ e R $\$ 31.799,28$ ha $^{-1}$, e TIR de $35,5 \%$ e $27,3 \%$ respectivamente, portanto valores acima dos observados no presente projeto. Porém, deve-se ressaltar que os autores consideraram taxa de juros de $6,75 \%$ ao ano. No presente estudo, observou-se que mesmo com taxa de juros próxima a $12 \%$ obteve-se VLP da ordem de R\$ $30.000,00$ e se considerada taxa de juros de $6,75 \%$ ao ano, no presente projeto o VPL seria de R $\$ 116.016,33$.

No caso do cultivo da teca (Tectona grandis), foi observado VPL positivo até uma taxa de desconto de $15 \%$, que no caso resultou em VPL de R $\$ 67,72 \mathrm{ha}^{-1}$ ano $^{-1}$, e, a TIR foi de $14 \%$ ao ano, quando se considerou uma taxa de juros de 10\% (Tsukamoto Filho et al., 2003). No mesmo estudo os autores citam que as reduções nas receitas, com a queda do preço da madeira de teca, não podem ser de $25 \%$, mantidos outros fatores da análise, pois nesse caso inviabilizaria o projeto. Portanto, nesse caso, também foi observada vantagem econômica do projeto com mogno africano, onde o VPL foi significativamente maior e somente uma queda superior a $25 \%$ no preço da madeira tornaria o VPL negativo.

\section{Conclusão}

Plantio de Kaya ivorensis em pequena propriedade, com ciclo de 20 anos, é um projeto viável e apresenta baixa sensibilidade às variações do mercado.

\section{Referências}

Afonso Júnior, P. C. et al. Viabilidade econômica de produção de lenha de eucalipto para secagem de produtos agrícolas. Engenharia Agrícola, v. 26, n. 1, p. 28-35, 2006. DOI: 10.1590/S010069162006000100004.

Alvares, C. A. Köppen's climate classification map for Brazil. Meteorologische Zeitschrift, v. 22, n. 6, p. 711-728, 2014. DOI: 10.1127/0941-2948/2013/0507.

Banco Central do Brasil. Consulta à taxa selic diária. 2016a. Disponível em: $<$ http://www.bcb.gov.br/htms/selic/selicdiarios.asp $>$. Acesso em: 10 out. 2016.

Banco Central do Brasil. Histórico das taxas de juros. 2016 b. Disponível em: <https:/www.bcb.gov.br/Pec/Copom/Port/taxaSelic. asp>. Acesso em: 10 out. 2016.

Banco Central do Brasil. Histórico de metas para a inflação no Brasil. 2016c. Disponível em: <http:/www.bcb.gov.br/Pec/metas/ TabelaMetaseResultados.pdf>. Acesso em: 10 out. 2016.

Carvalho, A. M. de et al. Avaliação da usinagem e caracterização das propriedades físicas da madeira de Mogno Africano (Khaya ivorensis A. Chev.). Cerne, v. 16, suplemento, p. 106-114, 2010.

Dal Zot, W. Matemática financeira. 4. ed. Porto Alegre: Ed. da UFRGS, 2006.

Danquah, A. J. et al. Eco-geographic variation in leaf morphology of african mohogany (Khaya anthotheca and Khaya ivorensis) provenance in Gana. European Journal of Scientific Research, v. 51, p. 18-28, 2011.

Falesi, I. C. \& Baena, A. R. C. Mogno-africano Khaya ivorensis A.Chev. em sistema silvipastoril com leguminosa e revestimento natural do solo. Belém, PA: Embrapa Amazônia Oriental, 1999. (Embrapa Amazônia Oriental. Documentos, 4).

Figueiredo, E. O. et al. Teca (Tectona grandis L.f.): principais plantas do futuro empreendedor florestal. Rio Branco, AC, Brasil, 2005.

Gitman, L. J. Princípios de administração financeira. 2 ed. São Paulo: Pearson, 2000.

Gomes, D. M. Análise de viabilidade técnica, econômicofinanceiro para implantação da cultura do Mogno-Africano (Khaya ivorensis A. Chev.) na região oeste de Minas Gerais. 2010. Trabalho de Conclusão de Curso (Especialista em Gestão Florestal) - Universidade Federal do Paraná, Curitiba. Disponível em: <http:// www.pecca.com.br/pos/florestal/tccs/daniel_gomes.pdf $>$. Acesso em: 7 out. 2016.

International Tropical Timber Organization. Tropical Timber Market Report, v. 17, n. 2, 2013.

Janoselli, H. R. D. et al. 2016. Viabilidade econômica da produção de eucalipto no interior de São Paulo. Revista iPecege, v. 2, p. 24-45, 2016. DOI: 10.22167/r.ipecege.2016.2.24. 
Lamprecht, H. Silvicultura nos trópicos: ecossistemas florestais e respectivas espécies arbóreas: possibilidade e métodos de aproveitamento sustentado. Eschborn: Dt Ges. für Techn. Zusammenarbeit, 1990.

Lapponi, J. L. Avaliação de projetos e investimentos: modelos em excel. São Paulo: Lapponi, 1996. 264 p.

Mathias, J. Mogno africano: com madeira de qualidade e boa demanda internacional, a árvore é alternativa interessante para silvicultores e para quem quer ocupar espaço ocioso na propriedade. Globo Rural, 2012. Disponível em: <http://revistagloborural.globo. com/Revista/Common/0,,ERT152905-18293,00.html>. Acesso em: 8 out. 2016.

Oliveira, A. de D. et al. Análise econômica de um sistema agro-silvopastoril com eucalipto implantado em região de cerrado. Ciência Florestal, v.10, p. 1-19, 2000.

Parque Florestal. Mogno africano: lucratividade. 2016. Disponível em: $<$ http://www.parqueflorestal.com.br/lucratividade $>$. Acesso em: 14 out. 2016.

Rezende, J. L. P. \& Oliveira, A. D. Análise econômica e social de projetos florestais. Viçosa, MG, 2001.

Ribeiro, A. et al. O cultivo do mogno africano (Khaya spp.) e o crescimento da atividade no Brasil. Floresta e Ambiente, v. 24, 2017.

Rosa, F. O. Zoneamento edafoclimático e respostas do mogno africano às condições do Cerrado. 2014. 77 f. Dissertação (Mestrado em Agronomia: Solo e Água) - Universidade Federal de Goiás, Goiânia. Disponível em: < http://repositorio.bc.ufg.br/tede/ handle/tede/5972>. Acesso em: 15 out. 2018.
Samanez, C. P. Engenharia econômica. São Paulo: Pearson Prentice Hall, 2009.

Silva, J. G. M. et al. Qualidade da madeira de mogno africano para a produção de serrados. Scientia Forestalis, v. 44, n. 109, p. 181-190, 2016. DOI: $10.18671 /$ scifor.v44n109.18.

Sistema Brasileiro de Classificação de Solos. Brasília, DF: Embrapa Produção de Informação; Rio de Janeiro: Embrapa Solos, 1999. $412 \mathrm{p}$.

Sistema Meteorológico do Paraná. 2016. Disponível em: <http:// www.simepar.br>. Acesso em: 18 set. 2016.

Teixeira, V. C. M. Avaliação da usinagem da madeira de mogno africano (Khaya ivorensis A. Chev.). 2011. Monografia (Engenheiro Florestal) - Universidade Federal Rural do Rio de Janeiro Instituto de Florestas, Seropédica.

Tsukamoto Filho, A. de A. et al. Análise econômica de um plantio de teca submetido a desbastes. Revista Árvore, v. 27, n. 4, p. 487-494, 2003. DOI: 10.1590/S0100-67622003000400009.

UOL Economia. UOL economia cotações: câmbio. 2017. Disponível em: $<$ https://economia.uol.com.br/cotacoes/cambio/euro-uniaoeuropeia/?historico>. Acesso em: 1 set. 2017.

Vitale, V. \& Miranda, G. de M. Análise comparativa da viabilidade econômica de plantios de Pinus taeda e Eucalyptus dunnii na região centro-sul do Paraná. Revista Floresta, v. 40, n. 3, p. 469-476, 2010.

Ward, S. et al. Special issue: sustainable management of high-value timber species of the Meliaceae. Forest Ecology and Management, v. 255 , n. 2, p. 265-364, 2008. DOI: 10.1016/j.foreco.2007.09.047. 